\title{
Human genetics of mycobacterial disease
}

\author{
Monica Dallmann-Sauer ${ }^{1,2,3} \cdot$ Wilian Correa-Macedo ${ }^{1,2,4} \cdot$ Erwin Schurr $^{1,2,3,4}(\mathbb{0}$
}

Received: 30 March 2018 / Accepted: 23 July 2018 / Published online: 16 August 2018

(c) The Author(s) 2018

\begin{abstract}
Mycobacterial diseases are caused by members of the genus Mycobacterium, acid-fast bacteria characterized by the presence of mycolic acids within their cell walls. Claiming almost 2 million lives every year, tuberculosis (TB) is the most common mycobacterial disease and is caused by infection with M. tuberculosis and, in rare cases, by M. bovis or M. africanum. The second and third most common mycobacterial diseases are leprosy and buruli ulcer (BU), respectively. Both diseases affect the skin and can lead to permanent sequelae and deformities. Leprosy is caused by the uncultivable M. leprae while the etiological agent of BU is the environmental bacterium M. ulcerans. After exposure to these mycobacterial species, a majority of individuals will not progress to clinical disease and, among those who do, inter-individual variability in disease manifestation and outcome can be observed. Susceptibility to mycobacterial diseases carries a human genetic component and intense efforts have been applied over the past decades to decipher the exact nature of the genetic factors controlling disease susceptibility. While for BU this search was mostly conducted on the basis of candidate genes association studies, genome-wide approaches have been widely applied for TB and leprosy. In this review, we summarize some of the findings achieved by genome-wide linkage, association and transcriptome analyses in TB disease and leprosy and the recent genetic findings for BU susceptibility.
\end{abstract}

\section{Introduction}

A common observation in human infectious diseases is that contact with pathogens is necessary but not sufficient for infection and subsequent development of clinical disease. Environmental and host factors, including the host genetic background, play a crucial role in the outcome of microbial exposure (Alcaïs et al. 2009; Casanova and Abel 2013). In mycobacterial diseases, an example that demonstrates the inherent spectrum of susceptibility to clinical disease is a

Monica Dallmann-Sauer and Wilian Correa-Macedo have contributed equally to this work.

Erwin Schurr

erwin.schurr@mcgill.ca

1 Program in Infectious Diseases and Immunity in Global Health, Research Institute, McGill University Health Centre, Montreal, QC, Canada

2 The McGill International TB Centre, McGill University, Montreal, QC, Canada

3 Departments of Human Genetics and Medicine, Faculty of Medicine, McGill University, Montreal, QC, Canada

4 Department of Biochemistry, Faculty of Medicine, McGill University, Montreal, QC, Canada tragic event known as the Lübeck disaster. In 1929, before the advent of antibiotics, 251 newborns were inoculated with Bacillus Calmette-Guérin (BCG) vaccine accidentally contaminated with virulent Mycobacterium tuberculosisthe etiological agent of tuberculosis (TB) (Fox et al. 2016). As a consequence, 228 infants developed clinical disease and 72 died from TB within a year of inoculation. Overall, $68 \%$ of those who had developed clinical TB recovered spontaneously, indicating natural resistance to TB. Also, analysis of the available data indicated that different vaccine batches were contaminated with different amounts of M. tuberculosis. It was observed that the bacterial dose had an important impact on the outcome of such exposure, since increased mortality could be attributed to increased levels of M. tuberculosis contamination. Of note, children who had been inoculated with similar amounts of M. tuberculosis displayed a broad spectrum of clinical symptoms ranging from total absence of clinical disease to death. This suggested that host-related factors, such as the genetic background, play an important role in innate resistance to TB (Fox et al. 2016). More direct evidence that human genetics can determine the outcome of mycobacterial infections comes from studies on Mendelian susceptibility to mycobacterial disease (MSMD), a rare condition characterized by selective predisposition to 
clinical disease caused by weakly virulent mycobacteria species. Studies of MSMD resulted in the identification of multiple rare single-gene mutations in genes encoding proteins of the IL12 and IFN- $\gamma$ pathway as cause of susceptibility to mycobacterial disease (Boisson-Dupuis et al. 2015; Casanova 2015). At the population level, genetic studies have been performed to better understand the role of the human genetic background for the eventual outcome of mycobacterial infection, mainly TB and leprosy-the two most common mycobacterial diseases. Here, we provide an overview of selected findings obtained by genome-wide approaches used in the search of human genetic predisposition to clinical TB disease and leprosy. We also summarize initial genetic findings obtained for buruli ulcer (BU), the third most common mycobacterial disease.

\section{Tuberculosis}

Tuberculosis is caused by M. tuberculosis and can affect any part of the body but most commonly affects the lungs leading to pulmonary TB (PTB). In 2016, the estimated TB incidence was 10.4 million new cases worldwide and nearly 1.7 million deaths due to the disease, including almost 0.4 million deaths among HIV-positive individuals (WHO 2017a). Exposure to M. tuberculosis leads to elimination of the pathogen and no persistent infection in $20-50 \%$ of individuals (Abel et al. 2014). Absence of persistent infection is inferred from a negative tuberculin skin test (TST) and/ or IFN- $\gamma$ release assay (IGRA) in individuals exposed to the pathogen (Pai et al. 2016). The identification of a major human genetic component linked to lack of TST reactivity in subjects exposed to M. tuberculosis expands the role of genetic factors to infection resistance (Cobat et al. 2009, 2015). Genetic findings of infection resistance to M. tuberculosis were recently reviewed elsewhere (Abel et al. 2017; Orlova and Schurr 2017; Simmons et al. 2018). Among individuals infected with $M$. tuberculosis, a person can remain in an asymptomatic state known as latent TB infection (LTBI) and never develop clinical disease or can evolve to clinical TB (active TB), whether it is primary TB or PTB (Abel et al. 2014; Pai et al. 2016). Primary TB is characterized by clinical disease that occur shortly after infection, either without LTBI or after a very short LTBI phase. While the majority of TB cases occur shortly ( $<1$ years) after infection (Sloot et al. 2014), among children progression of infection often leads to extrapulmonary, disseminated disease (severe primary TB). On the other hand, PTB occurs mostly in adults and is characterized by chronic pulmonary infection that can cause extensive lung damage (Abel et al. 2014; Pai et al. 2016). Different types of genetic control might explain these distinct outcomes of TB infection where, at one end of the spectrum, single-gene variations predispose individuals to severe childhood TB while older age disease involves more complex and polygenic factors (Alcaïs et al. 2005, 2010).

\section{Genome-wide linkage studies}

Several genome-wide linkage studies (GWLS) identified chromosomal regions co-segregating with clinical TB within families (Table 1), but only in some of those regions have candidate genes been associated with disease in follow-up studies (Orlova and Schurr 2010). In families from South Africa and The Gambia, a two-stage GWLS revealed two suggestive linkage peaks on chromosomes $15 q$ and Xq (Table 1) (Bellamy et al. 2000). An association study conducted in the same families from the GWLS and additional families from Guinea identified UBE3A on chromosome region $15 \mathrm{q}$ as a candidate gene for TB susceptibility (Cervino et al. 2002). In Brazilian families with PTB cases, three chromosomal regions-10q26.13, 11q12.3 and 20p12.1 - showed suggestive evidence for linkage with disease (Table 1) (Miller et al. 2004). A GWL scan for PTB conducted in 48 Moroccan families followed by fine mapping linkage analysis of suggestive findings in an extended population of 96 families found chromosome region 8q12-q13 significantly linked to PTB (Table 1) (Baghdadi et al. 2006). In a follow-up study, 3216 SNPs within this region were genotyped in a family-based association study in a sample including 286 offspring with PTB from Morocco (Grant et al. 2013). Stepwise replication and validation in independent population samples from Morocco and Madagascar found association between PTB and a cluster of SNPs with high linkage disequilibrium overlapping the 3 ' region of the TOX gene. Interestingly, the protein encoded by this gene plays a role in the development of $\mathrm{T}$ cells, including CD4+ T cells (Aliahmad et al. 2012). An important finding in this study was that TOX association with PTB was driven by early-onset PTB cases ( $<25$ years old) (Grant et al. 2013). The detection of an age-dependent association highlights the importance of considering age-of-onset in association studies of PTB.

A GWLS performed in families from Malawi and South Africa found chromosome regions 6p21-q23 and 20q13.31-33 as PTB susceptibility loci (Table 1) (Cooke et al. 2008). In the same study, 40 SNPs in the 20q13.31-33 region were tested for association in an independent population from West Africa and found variants of the $M C 3 R$ and CTSZ genes associated with PTB. Subsequently, variants in both genes were found associated with PTB in an independent case-control population from South Africa (Adams et al. 2011), while only the $M C 3 R$ gene was found associated with disease in an Iranian sample (Hashemi et al. 2013). The linkage hit on chromosome 20q13 was replicated and an additional peak on chromosome 7p22-p21 with suggestive evidence of linkage with PTB was detected 
Table 1 Summary of loci linked to PTB by genome-wide linkage studies

\begin{tabular}{|c|c|c|c|}
\hline Reference $^{\mathrm{a}}$ & Population sample & Locus $^{b}$ & Study statistical metrics / Notes ${ }^{\mathrm{c}, \mathrm{d}}$ \\
\hline \multirow[t]{2}{*}{ Bellamy et al. (2000) } & \multirow{2}{*}{$\begin{array}{l}136 \text { South African and Gambian families ( } 83 \text { families } \\
\text { in the discovery phase), including } 173 \text { sibpairs }\end{array}$} & $15 q$ & LOD score $=2.00, p=0.001$ \\
\hline & & $\mathrm{Xq}$ & LOD score $=1.77, p=0.002$ \\
\hline \multirow[t]{3}{*}{ Miller et al. (2004) } & \multirow{3}{*}{$\begin{array}{l}38 \text { Brazilian families ( } 16 \text { families in the discovery } \\
\text { phase), including } 105 \text { affected offspring }\end{array}$} & $10 q 26.13$ & LOD score $=1.31, p=0.007$ \\
\hline & & $11 \mathrm{q} 12.3$ & LOD score $=1.85, p=0.002$ \\
\hline & & $20 \mathrm{p} 12.1$ & LOD score $=1.78, p=0.002$ \\
\hline Baghdadi et al. (2006) & $\begin{array}{l}96 \text { Moroccan families ( } 48 \text { families in the discovery } \\
\text { phase), including } 227 \text { affected siblings }\end{array}$ & $8 q 12-q 13$ & MLB LOD score $=3.49, p=3 \times 10^{-5}$ \\
\hline \multirow[t]{2}{*}{ Cooke et al. (2008) } & \multirow{2}{*}{$\begin{array}{l}105 \text { Malawian and South African families, including } \\
155 \text { affected sibpairs ( } 71 \text { sibpairs from South Africa } \\
\text { in the discovery phase) }\end{array}$} & $6 \mathrm{p} 21-\mathrm{q} 23$ & LOD score $=1.9, p=0.002$ \\
\hline & & $20 \mathrm{q} 13.31-33$ & LOD score $=3.1, p=10^{-4}$ \\
\hline \multirow[t]{2}{*}{ Stein et al. (2008) } & \multirow{2}{*}{$\begin{array}{l}193 \text { Ugandan families ( } 95 \text { families in the discovery } \\
\text { phase), including } 258 \text { full sibling pairs and } 175 \text { half } \\
\text { sibling pairs }\end{array}$} & $7 \mathrm{p} 22-\mathrm{p} 21$ & $p=0.0002$ \\
\hline & & $20 \mathrm{q} 13$ & $p=0.002$ \\
\hline \multirow[t]{3}{*}{ Mahasirimongkol et al. (2009) } & \multirow[t]{3}{*}{93 Thai families (195 affected individuals) } & $5 q 23.2-31.3$ & LOD score $=2.29$, empirical $p=0.0005$ \\
\hline & & $17 \mathrm{p} 13.3-13.1$ & $\begin{array}{l}\text { Ordered subset analysis by TB age-of- } \\
\text { onset: LOD score }=2.57 \text {, permutation } \\
p=0.0187\end{array}$ \\
\hline & & $20 \mathrm{p} 13-12.3$ & $\begin{array}{l}\text { Ordered subset analysis by TB age-of- } \\
\text { onset: LOD score }=3.33 \text {, permutation } \\
p=0.0183\end{array}$ \\
\hline
\end{tabular}

$L O D$ logarithm of the odds; $M L B$ maximum likelihood binomial

${ }^{a}$ Follow-up association analysis of candidate genes located in the regions linked to the disease are not included in this table

${ }^{b}$ For studies in which the population sample consists of an extension of a previous published GWLS, only the new findings from the extended population analysis are shown

${ }^{c}$ Peak/maximum LOD score is shown for each locus when available

${ }^{\mathrm{d}}$ In multi-stage studies, results shown are from the combined analysis with all families when available

in a GWLS of families from Uganda (Stein et al. 2008). A SNP-based GWLS was conducted in 93 multiplex Thai families, including 195 individuals affected with TB (Mahasirimongkol et al. 2009). Chromosome region 5q23.2-31.3 showed evidence of suggestive linkage with TB and two candidate loci on chromosome regions $17 \mathrm{p} 13.3-13.1$ and 20p13-12.3 showed evidence of linkage with earlier onset of TB (Table 1). Recently, a 1Mbp region underlying the linkage peak on 20p13-12.3 was sequenced in 13 TB cases from the GWLS Thai families to select functional candidate variants to be tested in association studies in case-control samples from Thailand (Nakauchi et al. 2016). Variants in the ITPA gene were identified as risk factor for TB in patients with age-of-onset younger than 45 years of age.

\section{Genome-wide association studies}

The first genome-wide association study (GWAS) for PTB was conducted in 2237 cases and 3122 controls from Ghana and The Gambia followed by stepwise replication of SNPs with suggestive significance in two populations from Ghana and one from Malawi (Table 2) (Thye et al. 2010). A single SNP on chromosome region 18q11.2 within a non-coding chromosomal segment was identified as susceptibility locus for TB. When the genotypes of additional variants were imputed and included in the analysis of the genome-wide Ghanaian data, a TB-protective locus was found on chromosome $11 \mathrm{p} 13$ downstream of the WT1 gene (Table 2) (Thye et al. 2012). The association signal in $11 \mathrm{p} 13$ was validated in Gambian and Russian population samples (Thye et al. 2012), as well as in a South African (Chimusa et al. 2014) and a Moroccan sample (Grant et al. 2016). In contrast, only a trend toward association was found in Indonesian patients (Thye et al. 2012). On the other hand, validation of the GWAS findings for 18q11.2 in different populations proved more difficult. This locus was found associated with TB in a Han Chinese cohort (Wang et al. 2013), but in the opposite direction of association than the first TB GWAS (Thye et al. 2010). No association was found in three additional independent Chinese population samples (Dai et al. 2011; Ji et al. 2013; Miao et al. 2016) or in a South African sample (Chimusa et al. 2014). In a Taiwanese sample, association of rs4331426 was found only in Taiwanese women (Lee et al. 2016). When meta-analysis was performed including the aforementioned Chinese and Taiwanese populations with a total of 3118 TB patients and 3226 controls, rs4331426 SNP in 18q11.2 was found not to be associated with TB (Miao et al. 2016). Conflicting results for this locus were also found 


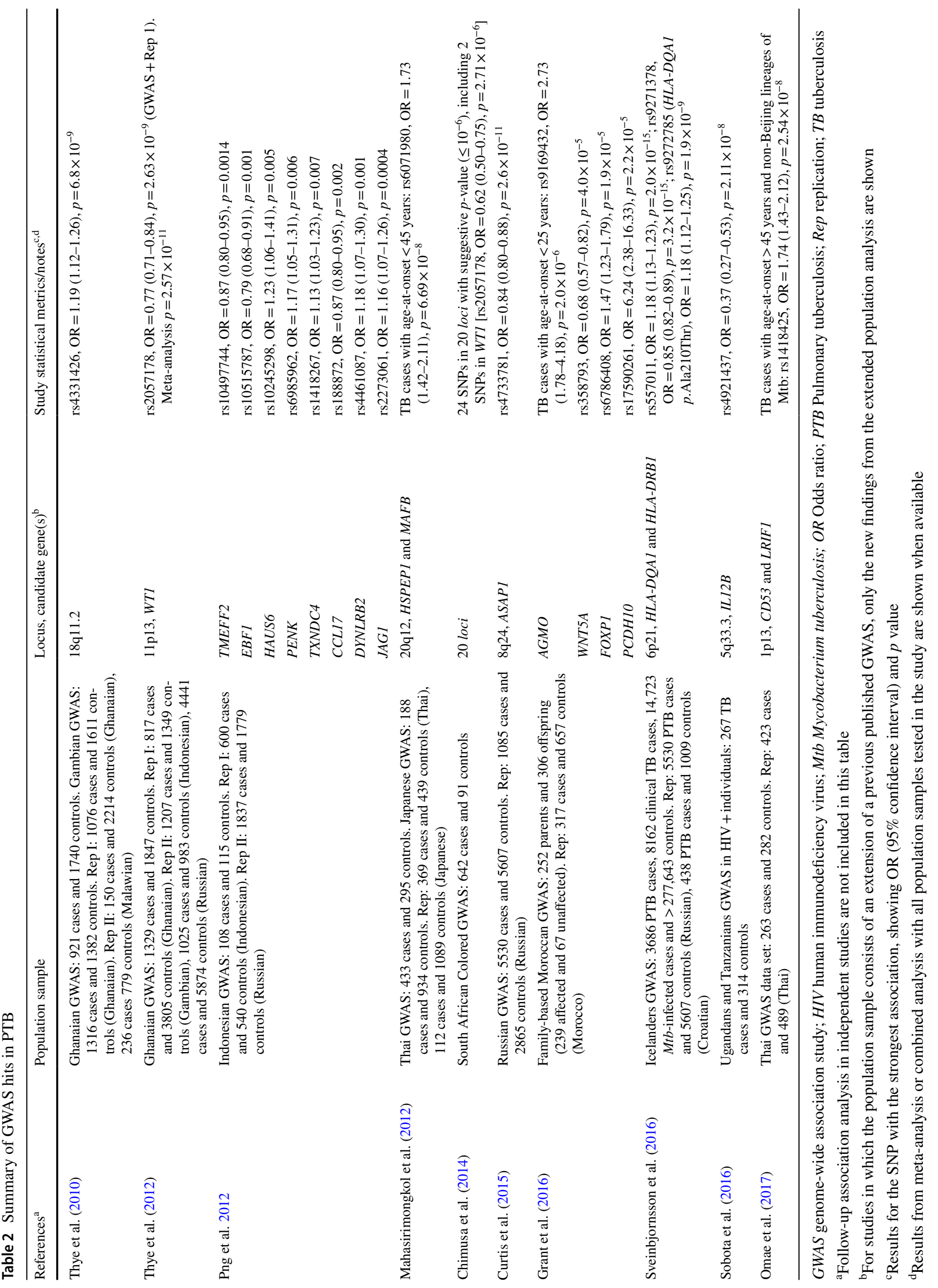


between a family-based and a case-control sample of a PTB GWAS employing a Moroccan sample (Grant et al. 2016).

In a GWAS from Indonesia, nearly 95,000 SNPs were tested for association in $108 \mathrm{~TB}$ cases and 115 controls (Png et al. 2012). Stepwise replication was conducted for SNPs with $p<0.05$ in independent Indonesian and Russian samples. Suggestive evidence of association was found between PTB and SNPs in 8 loci (Table 2), including several that are located within genes of the pro-inflammatory Th1 response IFN- $\gamma$ pathway. A GWAS conducted in Thai and Japanese populations did not identify any significant genetic risk factors for TB; however, when TB cases were stratified by ageof-onset, an association was found between variants of the HSPEP 1 and MAFB genes and TB cases with age-of-onset less than 45 years (Mahasirimongkol et al. 2012). Moreover, to consider the heterogeneity of the pathogen genome, the Thai GWAS data were stratified by M. tuberculosis lineage [Beijing (39\%) vs. non-Beijing lineages (61\%)] (Omae et al. 2017). This approach revealed the association of a SNP on chromosome region $1 \mathrm{p} 13$ and late-onset TB caused by bacilli belonging to non-Beijing lineages (Table 2). This SNP is located in an intergenic region between the CD53 and $L R I F 1$ genes. Interestingly, CD53 expression was higher in patients with active TB disease when compared to healthy controls or LTBI cases (Omae et al. 2017).

In a Russian sample, a GWAS for PTB was conducted in which 7.6 million variants-genotyped and imputedwere analyzed for association with PTB in 5530 patients and 5607 controls (Curtis et al. 2015). A total of 11 SNPs located in intronic regions of the ASAP1 gene showed evidence for genome-wide significance of association with PTB (Table 2). These findings were successfully replicated in a second case-control Russian sample (Curtis et al. 2015). Interestingly, $A S A P 1$ expression was reduced in dendritic cells (DCs) after stimulation with $M$. bovis BCG and $M$. tuberculosis, and the level of reduction correlated with the genotype of an associated SNP. Moreover, ASAP1-depleted DCs showed slower velocity of migration than control cells in in vitro assays, which might play a role in TB pathogenesis by delaying the adaptive immune response (Curtis et al. 2015). However, SNPs in the ASAPl gene were not associated with PTB in Western Chinese and Tibetan population samples (Hu et al. 2016), a family-based GWAS in Morocco (Grant et al. 2016) or a case-control GWAS in Iceland (Sveinbjornsson et al. 2016). In the GWAS conducted in North Africa, 558 individuals in a family-based discovery Moroccan sample were recruited for a GWAS of PTB and suggestive findings were tested for association in an independent case-control Moroccan population sample (Table 2) (Grant et al. 2016). Two intronic SNPs-in the $A G M O$ and $F O X P 1$ genes - and two intergenic SNPs - near $W N T 5 A$ and $P C D H 10$, respectively-showed suggestive evidence for association with PTB. The AGMO association was found only in the $<25$ years old subset. Interestingly, $A G M O$ and FOXP 1 are involved in the function of macrophages, cells that play an important role in TB pathogenesis (Grant et al. 2016). The Icelandic GWAS which employed both LTBI and clinical disease as outcomes included 3686 PTB patients, 14,724 M. tuberculosis-infected cases (made up of LTBI and clinical TB cases), and nearly 300,000 controls (Sveinbjornsson et al. 2016). Three SNPs in the human leukocyte antigen (HLA) class II region were associated with M. tuberculosis infection and/or PTB with modest effect on phenotype expression (Table 2). These findings were validated in Russian and Croatian PTB case-control samples (Sveinbjornsson et al. 2016). Two of those SNPs are located between $H L A-D Q A 1$ and $H L A-D R B 1$ while the third SNP is a missense variant (p.Ala210Thr) in the HLA-DQAl gene that represents the $H L A-D Q A I^{*} 03$ super allele.

In a recent GWAS, an interesting approach was used which led to the identification of a TB-protective locus with strong effect (Sobota et al. 2016). This study enrolled only HIV-positive individuals from prospective TB cohorts in Uganda and Tanzania, where TB is hyperendemic. After 8-years follow-up, $267 \mathrm{HIV}$-infected patients developed clinical TB while 314 did not, and these groups were included in the GWAS as cases and controls, respectively. Due to immunosuppression, HIV-positive patients exposed to $M$. tuberculosis are at higher risk to progress to active TB. Hence, identification of HIV-positive individuals in TB hyper-endemic regions that do not develop TB disease provides a strong TB resistance phenotype. Following this hypothesis, the GWAS in Uganda and Tanzania identified a SNP located in an intron of the $U B L C P 1$ gene and $51 \mathrm{~kb}$ downstream from $I L 12 B$ as protective for TB disease in highly susceptible individuals (Table 2). This SNP aligns to a known H3K27Ac histone mark which suggests it is involved in gene expression regulation (Sobota et al. 2016).

So far, a common theme underlying the search for genetic factors controlling susceptibility to TB, no matter the technical platform or biological feature investigated, is the difficulty of replication. Even within a self-contained phenotype as PTB, TB has itself revealed as a heterogeneous disease for which genetic susceptibility factors seem to vary depending on population sample, age-at-diagnosis, and $M$. tuberculosis lineages. Hence a first task is to define clearer TB phenotypes (e.g., TST/IGRA double positives, presence of granulomas, or extent of lung involvement), create study designs with tighter age groups and when possible, take into account the causative $M$. tuberculosis strain. On the genetics side, replication steps should not focus only on associated SNPs since signals that may be lost due to population specific LD pattern. Rather, fine mapping of implicated genes may yield more consistent replications. 


\section{Genome-wide RNA expression analysis}

Hypothesis-free transcriptome approaches have rapidly increased the knowledge of molecular events underlying a myriad of phenotypes. In TB, transcriptomics has been used to unravel mechanisms of pathogenesis for both M. tuberculosis infection and clinical TB disease. For instance, the study of genome-wide mRNA expression levels before and after infection with M. tuberculosis of monocyte-derived dendritic cells (DCs) from healthy individuals by microarray identified 3040 differentially expressed genes (Barreiro et al. 2012). Genes involved in immune responses were among those with the most significant changes in expression levels. Further analysis identified more than 700 genes with a cis-eQTL within $200 \mathrm{~kb}$ of their transcriptional start sites, including 96 and 102 genes with cis-eQTL only in infected and non-infected DCs, respectively (so-called response ciseQTL). When crossing these results with the first TB GWAS (Thye et al. 2010), SNPs with a nominal GWAS $p$ value of .05 were enriched among response cis-eQTL, but not among cis-eQTL (Barreiro et al. 2012).

Given the relative ease of sampling, transcriptomic biomarkers obtained from whole blood are attractive targets to derive minimal RNA signatures capable of discriminating resistance to infection or progression from LTBI to active PTB, and several studies tackled these goals aiming for potential applications in clinical settings (Berry et al. 2010; Maertzdorf et al. 2011; Kaforou et al. 2013; Anderson et al. 2014). With focus on progression from LTBI to PTB, a large prospective study screened and followed the clinical evolution of 6363 adolescents infected with M. tuberculosis for 6 months to 2 years (Zak et al. 2016). A total of 46 subjects progressed to active PTB and their blood transcriptomes were compared with the transcriptomes of $107 \mathrm{M}$. tuberculosis-infected subjects who remained free of TB. The samples were split in a training and test set and a 16 gene progression signature was identified. The signature predicted progression to active TB disease in a time-frame of up to 18 months prior to clinical disease. The predictive value of the signature increased for subjects that were closer to active disease. These findings were validated in three independent populations. Interestingly, the RNA signature was able to distinguish non-PTB diseases from active PTB (Zak et al. 2016). In a follow-up study, longitudinal transcriptome changes for type I/II interferon response genes, Th17-associated genes, and RNA transcript modules that correlated with different whole blood cellular sub-population were shown to be sequentially modulated over two years in TB progressors (Scriba et al. 2017).

A striking effect of $M$. tuberculosis infection has also been described for whole blood mRNA and miRNA over a $96 \mathrm{~h}$ time course in samples from non BCG-vaccinated healthy individuals (von Both et al. 2018). When considering differentially expressed (DE) genes with an absolute log fold change $>1,75 \%$ were down-regulated in response to $M$. tuberculosis. By investigating maximum fold changes in relation to time points for all DE genes, the maximum suppression was achieved within $48 \mathrm{~h}$ for genes involved in innate immunity while genes that were downregulated up to $96 \mathrm{~h}$ were those related to adaptive immunity. Independent experiments identified 97 DE miRNAs whose mRNA targets were over-represented among both down-regulated and all DE genes (von Both et al. 2018). Non-coding genes have previously been shown to be differentially expressed following $M$. tuberculosis infection (Siddle et al. 2014), and they have been suggested as putative markers of PTB (Chen et al. 2017) and as modulators of genes involved in autophagy (Etna et al. 2018).

Despite the promising results, study-specific signatures derived from microarray experiments have little or no overlap regarding the genes implicated (Blankley et al. 2016a). To overcome possible sample size limitations from microarray datasets and test new hypotheses, meta-analyses have been performed and identified novel and validated DE genes from individual studies (Blankley et al. 2016a; Wang et al. 2018). However, the number of DE genes is drastically reduced if consistency is required across all datasets. Although no gene signatures were reported, genes detected by meta-analyses implicated host response pathways, such as the type I interferon signaling cascade, that were consistently disturbed in TB. Evidence accumulated from blood transcriptome analyses across the TB pathogenesis spectrum (from infection to active disease) so far suggests that (i) RNA makers reflect various stages of TB progression rather than providing susceptibility makers; and (ii) that TB disease displays significant phenotypic heterogeneity (Scriba et al. 2017; Blankley et al. 2016b). In contrast to PTB, derivation of RNA expression profiles that discern LTBI from non-infected individuals remained a challenge (Wang et al. 2018). Nevertheless, recent work investigated the transcriptomic differences between $M$. tuberculosis infection-resistant and LTBI subjects and implicated histone deacetylase pathways as putative regulators of innate immunity to mycobacteria (Seshadri et al. 2017). The transcriptomic assays mentioned above contributed to the knowledge of host response to M. tuberculosis in tissues or cell-types that come in contact with the pathogen/antigens in a series of events that may define infection success. An aspect that deserves more attention is the characterization of cell types that act as first line defense. Alveolar macrophages likely serve this function and studying their response to $M$. tuberculosis in diverse ethnic cohorts may provide further insights (Maertzdorf et al. 2018). 


\section{Leprosy}

The etiological agent of leprosy, a chronic infectious disease, is the slow growing Mycobacterium leprae, which primarily affects the skin and peripheral nerves. Over the last 5 years the global leprosy incidence reported by the World Health Organization (WHO) was remarkably constant at approximately 210,000 patients (WHO 2017b). However, it is likely that these numbers are a severe underestimate of the true incidence (Smith et al. 2015). Leprosy presents along a spectrum of clinical phenotypes that are being classified employing different criteria (Gaschignard et al. 2016). Based on the WHO leprosy classification system, leprosy patients are classified as paucibacillary (PB) when presenting up to five lesions, or multibacillary (MB) when presenting more than five lesions. An important aspect of leprosy is that during or after treatment, some patients can manifest acute episodes of dysregulated inflammation known as leprosy reaction. As result of this condition, patients may experience pain and develop severe nerve damage and permanent sequelae. The most common form of reactional state is type 1 reaction (T1R), which can affect $30-50 \%$ of leprosy patients depending on the epidemiologic setting (Fava et al. 2012). There is accumulating evidence that human genetics plays an important role in leprosy susceptibility, with different sets of genes modifying host predisposition to leprosy per se, its clinical forms and reactional states (Sauer et al. 2015; Fava and Schurr 2016).

\section{Genome-wide linkage studies}

The first GWLS in leprosy detected a linkage peak on chromosome region 10p13 in Indian families with PB leprosy patients (Table 3) (Siddiqui et al. 2001). A subsequent genomic scan in a sample of Vietnamese families replicated linkage to the same region with PB leprosy (Mira et al. 2003). Based on these findings, the $M R C 1$ gene-located in the linked chromosomal interval—was selected as positional

Table 3 Summary of loci linked to leprosy by genome-wide linkage studies

\begin{tabular}{|c|c|c|c|}
\hline References $^{\mathrm{a}}$ & Population sample & Locus $^{\mathrm{b}}$ & Study statistical metrics/notes ${ }^{\mathrm{c}, \mathrm{d}}$ \\
\hline Siddiqui et al. (2001) & $\begin{array}{l}224 \text { Indian families ( } 93 \text { families in the discovery } \\
\text { phase), including } 245 \text { sibpairs }\end{array}$ & $10 \mathrm{p} 13$ & Multipoint LOD score $=4.09, p=0.000007$ \\
\hline Tosh et al. (2002) & $\begin{array}{l}233 \text { Indian families ( } 175 \text { families from Tamil Nadu; } \\
93 \text { families in the discovery phase), including } 256 \\
\text { sibpairs }\end{array}$ & $20 \mathrm{p} 12$ & $\begin{array}{l}\text { Single-point LOD score }=3.39, p=0.00003, \\
\text { multipoint } \text { LOD score }=1.29 \text { (Single-point } \text { LOD } \\
\text { score }=3.48 \text { and multipoint LOD score }=3.16 \text { in } \\
\text { families from Tamil Nadu) }\end{array}$ \\
\hline Mira et al. (2003) & $\begin{array}{l}86 \text { Vietnamese families, including } 205 \text { affected sib- } \\
\text { lings. Leprosy subtypes: } 10 \mathrm{MB} \text { families and } 17 \mathrm{~PB} \\
\text { families }\end{array}$ & $\begin{array}{l}6 \mathrm{p} 21 \\
6 \mathrm{q} 25-\mathrm{q} 27 \\
10 \mathrm{p} 13\end{array}$ & $\begin{array}{l}\text { Multipoint MLB LOD score }=2.62, p=2.5 \times 10^{-4} \\
\text { Multipoint MLB LOD score }=4.31, p=5 \times 10^{-6} \\
\text { PB: multipoint MLB LOD score }=1.74, p<0.003 \text {; } \\
\text { MB: multipoint MLB LOD score }=0.01 . \text { Hetero- } \\
\text { geneity } p=0.028\end{array}$ \\
\hline Miller et al. (2004) & $\begin{array}{l}71 \text { Brazilian families ( } 21 \text { families in the discovery } \\
\text { phase), including } 191 \text { affected offspring. Leprosy } \\
\text { subtypes: } 44 \text { LL families and } 39 \text { TT families }\end{array}$ & $\begin{array}{l}6 \mathrm{p} 21.32 \\
17 \mathrm{q} 22 \\
20 \mathrm{p} 13\end{array}$ & $\begin{array}{l}\text { LOD score }=3.23, p=5.8 \times 10^{-5} \\
\text { LOD score }=2.38, p=0.0005 \\
\text { LOD score }(\mathrm{D} 20 \mathrm{~S} 889)=1.51, p=0.004 . \text { LL: LOD } \\
\text { score }(\mathrm{D} 20 \mathrm{~S} 889)=1.36, p=0.006 . \text { TT: LOD } \\
\text { score }(\mathrm{D} 20 \mathrm{~S} 835)=0.74, p=0.033\end{array}$ \\
\hline Wallace et al. (2004) & $\begin{array}{l}185 \text { extended families from Malawi ( } 83 \text { nuclear fami- } \\
\text { lies in the discovery phase) }\end{array}$ & $21 \mathrm{q} 22$ & LOD score $=1.4, p \approx 0.001$ \\
\hline Yang et al. (2012) & 23 Chinese families, including 82 affected individuals & $\begin{array}{l}2 \mathrm{p} 14 \\
4 \mathrm{q} 22 \\
8 \mathrm{q} 24 \\
16 \mathrm{q} 24 \\
6 \mathrm{q} 24-\mathrm{q} 26\end{array}$ & $\begin{array}{l}\text { HLOD }=3.51(\text { REC }), \text { LOD score }=1.48, p=0.005 \\
\text { HLOD }=2.92(\text { DOM }), \text { LOD score }=1.21, p=0.009 \\
\text { HLOD }=2.74(\text { REC }), \text { LOD score }=1.22, p=0.009 \\
\text { HLOD }=1.93(\text { DOM }), \text { LOD score }=1.37, p=0.006 \\
\text { LOD score }=1.54, p=0.004\end{array}$ \\
\hline
\end{tabular}

$D O M$ dominant model; $H L O D$ heterogeneity logarithm of odds; $L O D$ logarithm of the odds; $L L$ lepromatous leprosy; $M B$ multibacillary leprosy; $M L B$ maximum likelihood binomial; $P B$ paucibacillary leprosy; REC Recessive model; $T T$ tuberculoid leprosy

${ }^{a}$ Follow-up association analysis of candidate genes located in the regions linked to the disease are not included in this table

${ }^{b}$ For studies in which the population sample consists of an extension of a previous published GWLS, only the new findings from the extended population analysis are shown

${ }^{\mathrm{c}}$ Peak/maximum LOD score is shown for each locus when available

${ }^{\mathrm{d}}$ In multi-stage studies, results shown are from the combined analysis with all families when available 
and functional candidate for association study since the protein encoded by this gene is a receptor for uptake of mycobacteria. Unexpectedly, in Vietnamese and Brazilian leprosy patients, $M R C l$ variants were associated with leprosy per se and MB leprosy, but not PB leprosy (Alter et al. 2010). In 2014, a gene-centered high-density association scan of the chromosomal 10p13 interval was conducted in two independent family-based population samples from Vietnam (Grant et al. 2014). Two independent association signals in the $C U B N$ and $N E B L$ genes were detected and, again, the association of both genes was with the MB clinical form. Additionally, the GATA3 gene, located $6.5 \mathrm{Mb}$ from the linkage peak on chromosome 10p13, was tested for association with leprosy and its clinical forms in two Brazilian population samples and a single SNP was associated with leprosy per se in both samples (Medeiros et al. 2016). Combined, these association studies identified one neighboring and three 10p13 genes involved in the control of leprosy susceptibility and the MB clinical form. Why genetic studies failed to detect an association with PB leprosy is perplexing and not known. It is possible that a collection of rare variants within this region impacts on the risk of PB leprosy but presently there are no deep sequencing data available to test this hypothesis (Orlova et al. 2011; Grant et al. 2014).

In addition to the linkage peak in the $10 \mathrm{p} 13$ region, chromosome region 6q25-q27 was linked to leprosy per se susceptibility in the same Vietnamese families (Table 3) (Mira et al. 2003). A fine mapping association study of 43 genes located in the 6q25-q27 region identified several SNPs located within the promoter region shared by two genes$P R K N$ (formerly PARK2, a well-known early onset Parkinson disease gene) and $P A C R G$ - associated with leprosy susceptibility in Vietnamese families (Mira et al. 2004). These results were validated in a Brazilian sample (Mira et al. 2004), but not in an Indian (Malhotra et al. 2006) and a Chinese sample (Li et al. 2012). Later, two studies performed high-density association mapping of the PRKN/PACRG regulatory region in independent population samples to analyze the impact of ethnic background on the association (Alter et al. 2013; Chopra et al. 2013). Both studies confirmed association and revealed that differences in linkage disequilibrium (LD) patterns across different ethnicities may explain the heterogeneity of association in previous studies between this locus and leprosy per se. Moreover, Alter et al. also demonstrated that the PRKN/PACRG association with the disease is dependent on the age-at-diagnosis: a more pronounced genetic effect is found in early-onset patients (Alter et al. 2013). Interestingly, the role of Parkin-the protein encoded by the PRKN gene-in host response against intracellular parasites has been demonstrated by functional assays. In different animal models, it was demonstrated that Parkin plays a role in the pathway that leads to degradation of intracellular pathogens-such as mycobacteria, salmonella and listeria-across distantly related species (Manzanillo et al. 2013). In addition, abrogation of PRKN in macrophages and Schwann cells affected their ability to produce IL-6 and CCL2-two key pro-inflammatory cytokines-in response to mycobacteria and lipopolysaccharides (de Léséleuc et al. 2013). Besides the PRKN/PACRG association, a recent study found a new gene located at chromosome 6q25-27-the SOD2 gene-as a risk factor for leprosy susceptibility in two independent Brazilian population samples (Ramos et al. 2016). Indeed, SOD2 expression was downregulated in the human acute monocytic leukemia cell lineage (THP-1) cells after stimulation with live M. leprae (Guerreiro et al. 2013).

The GWLS conducted in the Vietnamese families detected an additional leprosy linkage signal at the HLA complex on chromosomal region 6p21 (Table 3) (Mira et al. 2003). This region had previously been linked to leprosy susceptibility in a Brazilian sample (Miller et al. 2004). In fact, several studies have reported the involvement of HLA alleles and haplotypes as important genetic factors controlling susceptibility to leprosy (Geluk and Ottenhoff 2006; Jarduli et al. 2013). To further explore the region underlying the linkage peak at $6 \mathrm{p} 21$, a stepwise association study was conducted to scan a $10.4 \mathrm{Mb}$ region that encompasses 224 annotated genes within and centromeric to the HLA class II and class III regions (Alcaïs et al. 2007). A functional SNP was identified in the LTA promoter region as a risk factor of leprosy in ethnically distinct populations. Interestingly, the LTA genetic effect on leprosy risk was age dependent, since evidence for association became stronger with early ageat-diagnosis. To identify additional genetic risk factors for leprosy in the 6p21 chromosomal region, a high-density SNP association scan was conducted on a $1.9 \mathrm{Mb}$ chromosomal underlying the HLA complex (Alter et al. 2011). Employing samples from Vietnam and North India, SNPs in the HLA class I region were found associated with leprosy per se and strongly implicated the $H L A-C^{*} 15: 05$ allele in leprosy susceptibility. In addition to the above-mentioned genes in the HLA region, cumulative evidence indicated that the class III gene TNF was also involved in the immune response against leprosy. Specifically, a promoter variant located at position -308 of TNF has been extensively studied in leprosy, with inconsistent results (Cardoso et al. 2011b). Interestingly, a large association study conducted in four Brazilian population samples, followed by a meta-analysis including additional genotypes from published data, reinforced the TNF -308 protective effect in leprosy and suggested that the association is restricted to the Brazilian population (Cardoso et al. 2011a).

Complementary to these findings, several GWLS have reported other chromosomal regions involved in the control of leprosy phenotypes (Table 3) (Fava and Schurr 2016). Further analysis of the first leprosy GWL data with 
an extended Indian population found an additional linkage peak on chromosomal region 20p12 (Tosh et al. 2002). In Brazilian families with leprosy patients, suggestive evidence of linkage was found with the 17q22 and 20p13 chromosome regions (Miller et al. 2004). The latter linkage peak was located $3.5 \mathrm{Mb}$ distal to the linkage peak reported in the Indian sample. Moreover, chromosomal region 21q22 was linked to leprosy polarization in families from Malawi (Wallace et al. 2004). Finally, 2p14 was significantly linked to leprosy per se, while regions 4q22, 8q24 and 16q24 showed suggestive evidence for linkage in Chinese families (Yang et al. 2012). Leprosy susceptibility genes underlying these linkage peaks are yet to be identified.

\section{Genome-wide association studies}

The first leprosy GWAS was conducted in 2009 in four independent Chinese case-control samples (Zhang et al. 2009). Among the nearly 500,000 SNPs tested in the first population, 93 SNPs were associated with leprosy and reanalyzed in the three remaining case-control samples. In total, 15 SNPs located in five loci- $H L A-D R-D Q, R I P K 2$, TNFSF 15, NOD2 and CCDC122-LACC1-were significantly associated with leprosy $\left(p<1.00 \times 10^{-10}\right.$; Table 4$)$. Moreover, a trend toward association was found for one SNP near the LRRK2 gene (Table 4). Of note, most of these genes are implicated in Crohn's disease (Schurr and Gros 2009; Zhang et al. 2009; Grant et al. 2012). After the leprosy GWAS results, several association studies attempted to replicate these genes in independent populations. The NOD2 association with leprosy was validated in a Nepalese population, where it was also found associated with leprosy reaction (Berrington et al. 2010). $H L A-D R-D Q$ and CCDC122-LACC1 loci were associated with disease in population samples from India and West Africa (Wong et al. 2010b, a). Moreover, RIPK2 was validated in an Indian population (Marcinek et al. 2013), while LRRK2 was found to be associated with leprosy and the PB clinical form in Chinese and Indian population samples (Marcinek et al. 2013; Wang et al. 2015).

In a family-based Vietnamese sample, 16 significant GWAS SNPs were tested for association and SNPs tagging $H L A-D R-D Q, R I P K 2, N O D 2$ and CCDC122-LACC1 were validated as risk factors for leprosy susceptibility (Grant et al. 2012). Interestingly, when these families were stratified by the T1R status of leprosy patients, variants located in two genes that could not be replicated for leprosy per se-TNFSF 15 and LRRK2-were found associated with T1R (Fava et al. 2015, 2016). A total of 47 SNPs within TNFSF 15 and the adjacent TNFSF8 were found associated with T1R in Vietnamese patients. Moreover, $83 \%$ of SNPs were associated with TNFSF8 gene transcript levels in multiple tissues, indicating that, in fact, the association with T1R might be due to this gene and not TNFSF15 (Fava et al. 2015). One of the SNPs showed evidence of an agedependent genetic effect since the risk effect for T1R was stronger in younger than 30 years old patients $(\mathrm{OR}=1.95$, $95 \% \mathrm{CI}=1.54-2.46$, combined $\left.p=2.5 \times 10^{-8}\right)$ than in the global population sample $(\mathrm{OR}=1.46,95 \% \mathrm{CI}=1.23-1.73$, combined $p=1.5 \times 10^{-5}$ ) (Fava et al. 2017b). In LRRK2, the main SNP capturing the T1R association was a missense variant (M2397T) (Fava et al. 2016). This coding variant was known to impact LRRK2 protein turnover-where the protein with the M2397 allele presents shorter half-life than $2397 \mathrm{~T}$ - and was previously reported in association with Crohn's disease with the same risk allele as in T1R (M2397) (Liu et al. 2011; Fava et al. 2016). Subsequent eQTL analysis showed that nine variants belonging to the same SNP bin as M2397 promote an increase in LRRK2 expression only in non-stimulated cells. This indicated that these eQTL SNPs counterbalanced LRRK2 shorter halflife due to the M2397 variant by increasing mRNA expression levels. However, this compensatory mechanism was abrogated following stimulation with M. leprae (Fava et al. 2016). A stepwise association study of leprosy and the nonHLA genes that were significantly associated in the GWAS (RIPK2, TNFSF15, NOD2 and CCDC122-LACC1) was conducted in four independent Brazilian population samples (Sales-Marques et al. 2014). Initially, 36 SNPs were genotyped, capturing the complete information of the five genes, in a family-based population sample from Prata Village- an isolated, leprosy hyper-endemic population located in the Brazilian Amazon. Two SNPs located in NOD2 and CCDC122-LACC1 were associated with leprosy and were subsequently replicated in three independent Brazilian casecontrol population samples (Sales-Marques et al. 2014).

In 2011, an expanded analysis of the first GWAS (Zhang et al. 2009) was performed by combining the GWAS data set with additional control subjects leading to the identification of $I L 23 R$ and $R A B 32$ as additional leprosy associated genes in the Chinese sample (Table 4) (Zhang et al. 2011). Association of both genes was validated in Vietnamese families (Cobat et al. 2014). In two subsequent studies, the Chinese GWAS data set was further expanded (Table 4) (Liu et al. 2015; Wang et al. 2016). First, six additional loci were associated with leprosy when a second independent Chinese GWAS dataset was added to the previous GWAS dataset, followed by a two-stage replication in Chinese case-control samples (Table 4) (Liu et al. 2015). Finally, a third GWAS dataset was created by including results from a population-specific array in a three-stage GWAS meta-analysis comprising 8156 cases and 15,610 controls of Chinese ancestry (Wang et al. 2016). In addition to confirming all loci identified in the previous GWAS (Zhang et al. 2009, 2011; Liu et al. 2015), four novel loci were associated with leprosy (Table 4) 
Table 4 Summary of GWAS hits in leprosy phenotypes

\begin{tabular}{|c|c|c|c|}
\hline References $^{\mathrm{a}}$ & Population sample & Locus, candidate gene $(\mathrm{s})^{\mathrm{b}}$ & Study statistical metrics/notes ${ }^{\mathrm{c}, \mathrm{d}}$ \\
\hline Zhang et al. (2009) & $\begin{array}{l}\text { Chinese GWAS: } 706 \text { cases and } 1225 \text { controls. } \\
\text { Rep: } 2164 \text { cases and } 4373 \text { controls (Chinese), } \\
304 \text { cases and } 709 \text { controls (Chinese), } 786 \text { cases } \\
\text { and } 873 \text { controls (Chinese) }\end{array}$ & $\begin{array}{l}H L A-D R-D Q \\
\text { RIPK2 } \\
\text { TNFSF15 } \\
\text { LRRK2 } \\
\text { CCDC122 } \\
\text { LACC1 (C13orf31) } \\
\text { NOD2 }\end{array}$ & $\begin{array}{l}\mathrm{rs} 602875, \mathrm{OR}=0.67(0.62-0.72), p=5.35 \times 10^{-27} \\
\mathrm{rs} 42490, \mathrm{OR}=0.76(0.71-0.81), p=1.38 \times 10^{-16} \\
\mathrm{rs} 6478108, \mathrm{OR}=1.37(1.28-1.46), p=3.39 \times 10^{-21} \\
\mathrm{rs} 1873613, \mathrm{OR}=0.86(0.80-0.92), p=5.10 \times 10^{-5} \\
\mathrm{rs} 3088362, \mathrm{OR}=1.52(1.41-1.63), p=1.36 \times 10^{-31} \\
\mathrm{rs} 3764147, \mathrm{OR}=1.68(1.57-1.80), p=3.72 \times 10^{-54} \\
\mathrm{rs} 9302752, \mathrm{OR}=1.59(1.49-1.71), p=3.77 \times 10^{-40}\end{array}$ \\
\hline Zhang et al. (2011) & $\begin{array}{l}\text { Chinese GWAS: } 706 \text { cases and } 5581 \text { controls. } \\
\text { Rep: } 2307 \text { cases and } 4585 \text { controls (Chinese), } \\
273 \text { cases and } 214 \text { controls (Chinese), } 721 \text { cases } \\
\text { and } 500 \text { controls (Chinese) }\end{array}$ & $\begin{array}{l}1 \mathrm{p} 31.3, I L 23 R \\
6 \mathrm{q} 24.3, R A B 32\end{array}$ & $\begin{array}{l}\mathrm{rs} 3762318, \mathrm{OR}=0.69(0.62-0.77), p=3.27 \times 10^{-11} \\
\operatorname{rs} 2275606, \mathrm{OR}=1.30(1.21-1.39), p=3.94 \times 10^{-14}\end{array}$ \\
\hline Liu et al. (2015) & $\begin{array}{l}\text { Chinese GWAS (I): } 706 \text { cases and } 5587 \text { controls. } \\
\text { Chinese GWAS (II): } 842 \text { cases and } 925 \text { controls. } \\
\text { Rep I: } 2761 \text { cases and } 3038 \text { controls (Chinese). } \\
\text { Rep II: } 4004 \text { cases and } 6467 \text { controls (Chinese) }\end{array}$ & $\begin{array}{l}\text { 1q32.3, BATF3 } \\
5 \mathrm{p} 14.3, C D H 18 \\
9 \mathrm{q} 32, \text { DEC1 } \\
\text { 10q21.3, EGR2 } \\
\text { 11q13.1, CCDC88B } \\
16 p 13.13, \text { CIITA and SOCS1 }\end{array}$ & $\begin{array}{l}\operatorname{rs} 2221593, \mathrm{OR}=1.15, p=3.09 \times 10^{-8} \\
\operatorname{rs} 73058713, \mathrm{OR}=1.19, p=9.54 \times 10^{-9} \\
\operatorname{rs} 10817758, \mathrm{OR}=1.13, p=1.15 \times 10^{-8} \\
\operatorname{rs} 58600253, \mathrm{OR}=1.22, p=3.02 \times 10^{-12} \\
\operatorname{rs} 663743, \mathrm{OR}=1.24, p=8.84 \times 10^{-14} \\
\operatorname{rs} 77061563, \mathrm{OR}=0.84, p=6.23 \times 10^{-15}\end{array}$ \\
\hline Wang et al. (2016) & $\begin{array}{l}\text { Chinese GWAS (I): } 706 \text { cases and } 1223 \text { controls. } \\
\text { Chinese GWAS (II): } 840 \text { cases and } 924 \text { controls. } \\
\text { Chinese GWAS (III): } 1197 \text { cases and } 1426 \text { con- } \\
\text { trols. Rep I: } 1516 \text { cases and } 1512 \text { controls. Rep } \\
\text { II: } 3897 \text { cases and } 10525 \text { controls (Chinese) }\end{array}$ & $\begin{array}{l}3 \mathrm{p} 25.2, S Y N 2 \\
7 \mathrm{p} 14.3, \text { BBS9 } \\
8 \mathrm{p} 23.1, C T S B \\
8 \mathrm{q} 24.11, \text { MED30 }\end{array}$ & $\begin{array}{l}\mathrm{rs} 6807915, \mathrm{OR}=0.89, p=1.94 \times 10^{-8} \\
\mathrm{rs} 4720118, \mathrm{OR}=1.16, p=3.85 \times 10^{-10} \\
\mathrm{rs} 55894533, \mathrm{OR}=1.15, p=5.07 \times 10^{-11} \\
\mathrm{rs} 10100465, \mathrm{OR}=0.85, p=2.85 \times 10^{-11}\end{array}$ \\
\hline \multirow[t]{6}{*}{ Liu et al. (2017) } & \multirow[t]{6}{*}{$\begin{array}{l}\text { Chinese GWAS of protein-coding variants: } 1648 \\
\text { cases and } 2318 \text { controls. Rep I: } 3169 \text { patients } \\
\text { and } 9814 \text { controls (Chinese). Rep II: } 2231 \\
\text { patients and } 2266 \text { controls (Chinese) }\end{array}$} & $I L 23 R$ & $\begin{array}{l}\text { rs76418789 }(\mathrm{G} 149 \mathrm{R}), \mathrm{OR}=1.36(1.24-1.49) \\
\quad p=1.03 \times 10^{-10} \\
\mathrm{rs} 146466242(\mathrm{~K} 4022 *), \mathrm{OR}=1.45(1.31-1.61) \\
\quad p^{*}=3.39 \times 10^{-12}\end{array}$ \\
\hline & & NCKIPSD & $\begin{array}{l}\text { rs145562243 }(\mathrm{R} 176 \mathrm{Q}), \mathrm{OR}=4.35(2.58-7.35) \\
\quad p=1.44 \times 10^{-8}(\mathrm{GWAS}+\mathrm{Rep} \mathrm{I}) . \text { Meta-analysis } \\
p=1.71 \times 10^{-9}\end{array}$ \\
\hline & & $C A R D 9$ & $\begin{array}{l}\text { rs } 149308743(\mathrm{R} 494 \mathrm{H}), \mathrm{OR}=4.75(2.87-7.86) \\
\quad \begin{array}{l}p=4.99 \times 10^{-10}(\mathrm{GWAS}+\mathrm{Rep} \mathrm{I}) . \text { Meta-analysis } \\
p=2.09 \times 10^{-8}\end{array}\end{array}$ \\
\hline & & $S L C 29 A 3$ & $\begin{array}{l}\text { rs780668 }(\mathrm{S} 158 \mathrm{~F}), \mathrm{OR}=1.14(1.09-1.19) \\
\quad p=2.17 \times 10^{-9}\end{array}$ \\
\hline & & IL27 & $\begin{array}{l}\mathrm{rs} 181206(\mathrm{~L} 119 \mathrm{P}), \mathrm{OR}=0.83(0.78-0.89) \\
\quad p=1.08 \times 10^{-7}\end{array}$ \\
\hline & & $T Y K 2$ & $\begin{array}{l}\mathrm{rs} 55882956(\mathrm{R} 703 \mathrm{~W}), \mathrm{OR}=1.30(1.17-1.45) \\
\quad p=1.04 \times 10^{-6}\end{array}$ \\
\hline Fava et al. (2017a) & $\begin{array}{l}\text { Vietnamese GWAS in T1R: } 221 \text { families with } \\
229 \text { leprosy T1R-affected offspring and } 209 \\
\text { families with } 229 \text { leprosy T1R-free offspring. } \\
\text { Rep: } 253 \text { T1R cases and } 563 \text { T1R-free controls } \\
\text { (Vietnamese). Validation: } 471 \text { T1R cases and } \\
446 \text { T1R-free controls (Brazilians) }\end{array}$ & $\begin{array}{l}\text { 10p21.2, LOC } 105378318 / E \\
\quad \text { NSG00000235140 }\end{array}$ & $\begin{array}{l}\text { T1R: rs } 1875147, \mathrm{OR}=1.54(1.32-1.80) \\
\quad p=4.5 \times 10^{-8}\end{array}$ \\
\hline
\end{tabular}

$O R$ odds ratio; $R e p$ replication; $T 1 R$ type 1 reaction

${ }^{a}$ Follow-up association analysis in independent studies are not included in this table

${ }^{\mathrm{b}}$ For studies in which the population sample consists of an extension of a previous published GWAS, only the new findings from the extended population analysis are shown

${ }^{\mathrm{C}}$ Results for the SNP with the strongest association, showing OR (95\% confidence interval) and $p$ value when available

${ }^{\mathrm{d}}$ Results from meta-analysis or combined analysis with all population samples tested in the study are shown when available

(Wang et al. 2016). Finally, a genome-wide association study of protein coding genes and leprosy susceptibility has been conducted in a Chinese sample (Liu et al. 2017). In this study, 40,491 coding variants with minor allele frequency greater than $0.1 \%$ were tested for association in a discovery set composed of 3966 individuals (1648 cases). Then, stepwise replication was conducted in four independent Chinese population samples which led to identification of seven nonsynonymous variants that were associated with leprosy. These findings implicated six 
new genes in disease susceptibility-CARD9, FLG, IL27, NCKIPSD, SLC29A3 and TYK2-and also confirmed the association of the IL23R GWAS gene (Table 4).

Until now, only one GWAS for T1R risk in leprosy patients has been published. It was conducted in a familybased population sample composed of 221 Vietnamese families with 229 offspring with leprosy that were also T1R-affected and 209 families with 229 offspring with leprosy that were T1R-free (Fava et al. 2017a). In this GWAS, 6.3 million variants - genotyped and imputed-were tested for association in both family sets independently, followed by a heterogeneity test to detect associations that are specific to the T1R-affected subset. SNPs located between two recombination hot-spots on chromosome 10p21.2 were found preferentially associated with T1R. Stepwise replication of these findings in two independent case-control populations from Vietnam and Brazil allowed to narrow the association signal to a single eQTL SNP for a lncRNA gene as a risk factor for $\mathrm{T} 1 \mathrm{R}(\mathrm{OR}=1.54,95 \% \mathrm{CI} 1.32-1.80$, combined $p=4.5 \times 10^{-8}$ ) (Fava et al. 2017a).

GWLS, GWAS, and follow-up studies have contributed substantially to a better understanding of the human genetic factors involved in leprosy susceptibility. Moreover, not only have these studies led to the identification of genes and pathways that play a role in leprosy pathogenesis, but they have also identified covariates that may be critical for the genetic analyses of other complex diseases. For example, age-at-diagnosis, population samples size and phenotypic homogeneity, differences in LD pattern, and the effect of endophenotypes - for leprosy, T1R and leprosy subtypesall can impact on the detection and interpretation of genetic findings.

\section{Genome-wide RNA expression analysis}

RNA expression analyses have provided valuable data to better understanding leprosy pathogenesis. Comparisons of mRNA and miRNA expression between leprotic lesions and skin biopsies of healthy controls showed a large number of genes differentially expressed, including DE mRNAs and miRNAs exclusively detected in samples with leprosy reactions (Belone et al. 2015; Soares et al. 2017). Moreover, contrasting nerve biopsies of leprosy lesions against non-leprous neuropathy ones highlighted down-regulated cytokines and genes involved in mitochondrial metabolism as mediators of the host-M. leprae interplay (Guerreiro et al. 2013).

Recently, the impact of genetic variation on the human response to $M$. leprae was demonstrated by an eQTL study of whole blood cells in the presence and absence of M. leprae antigen (Manry et al. 2017). Of particular interest was the identification of genetic regulators of host gene expression levels that depended on the presence of M. leprae. Specifically, stimulation of whole-blood from leprosy patients with $M$. leprae sonicate identified 6675 genes differentially expressed $\left(p<4.2 \times 10^{-6}\right) ; 35 \%$ being up-regulated. Gene ontology term analysis showed that the majority of overexpressed genes were involved in immune system processes and immune related functions. Next, 1.7 million variants with minor allele frequencies $>10 \%$ and located within a $200 \mathrm{~kb}$ window of gene transcription start sites were tested for cis-eQTL effects. This led to the identification of 318 genes that were impacted by $c i s-\mathrm{eQTL}$ in either stimulated or non-stimulated samples (FDR of 0.01), while 66 of these genes displayed eQTL only in one condition (response eQTL) directly demonstrating the interaction of host genetic background and pathogen exposure. Interestingly, the same study also showed that both eQTL and response-eQTL are targeted by positive selection (Manry et al. 2017).

In an effort to derive transcriptome biomarkers for those leprosy patients who are at increased risk of developing $\mathrm{T} 1 \mathrm{R}$, the transcriptome response to $M$. leprae sonicate in whole blood from leprosy patient was compared between those patients who developed T1R and those who did not (Orlova et al. 2013). Employing retrospectively enrolled (i.e. cured) patients, compared to T1R-free patients a set of 44 genes was found preferentially upregulated in T1R patients of which 32 could be assigned to three functional groups: pro-inflammatory regulators, arachidonic acid metabolism mediators and regulators of anti- inflammation. Importantly, differentially upregulated genes allowed to derive a gene-set signature for T1R. The T1R signature was validated in a prospective study where blood from newly diagnosed T1R-free leprosy patients was stimulated with M. leprae antigen prior to the extraction of RNA. All patients were then followed for three years and the occurrence of T1R was recorded (Orlova et al. 2013). The enrichment of pro- and anti-inflammatory mediators among the T1R signature gene expression set prior to T1R onset suggests an innate defect in the regulation of the inflammatory response to M. leprae antigens.

\section{Buruli ulcer}

The third most common human mycobacterial disease is $\mathrm{BU}$, a necrotizing skin disease caused by Mycobacterium ulcerans, a toxin-producing environmental mycobacterium. The clinical presentations of $\mathrm{BU}$ are non-ulcerative or ulcerative lesions or osteomyelitis, located mainly in the limbs. Up to $22 \%$ of BU patients develop permanent functional sequelae, including amputations, which is associated with severe BU (presentation with large lesions, edema, osteomyelitis, or multifocal lesions) (Vincent et al. 2014). Cases of BU have been detected in more than 30 countries in Africa, the Western Pacific and South America. While, estimates for global incidence are presently not available (WHO 2017c), in 2016 only ten countries reported nearly 2000 BU cases 
to WHO (WHO 2017d). The disease is classified by WHO in three categories in terms of severity: (i) category I if the patient has one small lesion measuring $<5 \mathrm{~cm}$, (ii) category II if the patient presents non-ulcerative or ulcerative plaque, edema or one large lesion with maximum diameter between 5 and $15 \mathrm{~cm}$, and (iii) category III if presenting disseminated or mixed forms, multiple lesions or one extensive lesion measuring $>15 \mathrm{~cm}$ diameter (WHO 2012, 2017c). In some BU patients, a condition called paradoxical reaction (PR) can occur following the antibiotic treatment of M. ulcerans. PRs are characterized by intense inflammation in lesions and worsening clinical conditions after initial improvement (O’Brien et al. 2013).

\section{Candidate gene association studies}

As in TB and leprosy, following exposure of M. ulcerans there is a variability of outcome regarding both disease per se and the clinical manifestations of BU, suggesting that immune and genetic risk factors could play a role in this disease as well (Stienstra et al. 2001; Portaels et al. 2009; Vincent et al. 2014). This conclusion is further supported by family history of BU as risk factor for the disease (Sopoh et al. 2010). Fueled by these observations, association studies were designed to test candidate genes based on their previous implications in TB and/or leprosy and analysis of the implicated pathways. The first association study in BU was published in 2006 employing a Ghanaian casecontrol population sample (Stienstra et al. 2006). In this study, three SLC11A1 (formerly NRAMP1) variants were tested for association and one SNP was found significantly associated with BU susceptibility ( $\mathrm{OR}=2.89, p=0.004)$. Later, a case-control association study of nine SNPs in three autophagy-related genes-PRKN, NOD2 and ATG16L1was conducted in a population sample from Benin (Capela et al. 2016). The SNP rs 1333955 in $P R K N$ displayed an odds ratio of $1.43(p=0.05)$ risk of BU. The same SNP had previously been identified as main cause of the association of $P R K N$ with leprosy and also was shown to be a trans-eQTL for CCL2 and IL6 (de Léséleuc et al. 2013; Alter et al. 2013).

Considering severity of disease, two association signals in NOD2 were found for susceptibility to WHO category 3 when compared to combined category 1 and 2 [rs9302752 $\mathrm{OR}=2.23, p=0.02$ and $\mathrm{rs} 2066842(\mathrm{P} 268 \mathrm{~S}) \mathrm{OR}=12.7$, $p=0.03$ ]. Finally, ATG16Ll was found associated with protection from presenting the ulcerative phenotype $(\mathrm{OR}=0.35$, $p=0.02$ ). In 2016, four variants in SLC11A1 were genotyped in BU patients with clinical diagnosis of paradoxical reactions and $\mathrm{BU}$ patients without reaction from Ghana (Barogui et al. 2016). A TGTG indel located in the SLC11A1 $3^{\prime}$ UTR was associated with paradoxical reaction, revealing the homozygous ins/ins genotype as a risk factor to develop $\mathrm{PR}(\mathrm{OR}=7.19, p<0.001)$.

Recently, a case-control association study for BU and nine SNPs in six genes was performed in a case-control population sample from Ghana (Bibert et al. 2017). A trend toward association of a previously associated SLC11A1 SNP and $\mathrm{BU}$ predisposition was found $(\mathrm{OR}=1.63, p=0.06)$. In addition, SNPs in two genes were found as new candidates for BU risk factors: $I F N G \mathrm{rs} 2069705(\mathrm{OR}=1.56, p=0.007)$ and NOS2 rs9282799 (OR $=1.99, p=0.006)$. No association was detected between NOD2, PRKN and VDR SNPs and BU susceptibility. Moreover, a variable nucleotide tandem repeat (VNTR) located in intron 1 of $I F N G$, known to be in LD with rs2069705 was tested. When the two shorter length $\mathrm{CA}$ repeats were combined into a single allele, association to $\mathrm{BU}$ was found $(\mathrm{OR}=0.60, p=0.007)$. Moreover, since $I F N G$ rs2069705 and NOS2 rs9282799 are located in the promoter regions of these genes, in vitro assays demonstrated that both SNPs have an impact on gene expression. Interestingly, the $I F N G$ SNP only impacted on mRNA and protein expression levels following M. ulcerans but not M. marinum stimulation (Bibert et al. 2017).

Together, these candidate association studies provided initial evidence that host genetic factors play a role in predisposing to BU and its clinical subtypes. Still, replication and validation studies in independent populations are necessary to clarify the involvement of these genes in susceptibility to BU. Regarding candidate-free approaches, a recent study applied GWLS in a consanguineous family from Benin presenting two cases with extreme BU phenotype, which led to the identification of a region on chromosome 8 in linkage with the disease (Vincent et al. 2018). Exome sequencing was carried out on the affected siblings and a $37 \mathrm{~kb}$ homozygous deletion was found that overlapped a lincRNA and was located near a beta-defensin cluster. Next, data from an array scan in a cohort of $402 \mathrm{BU}$ cases and 401 controls from Benin was queried for the deletion which was found in two homozygous unrelated $\mathrm{BU}$ patients while none of the controls were homozygous for the deletion (Vincent et al. 2018). These findings further support the presence of genetic factors controlling susceptibly to $\mathrm{BU}$ and given the few studies in this disease, population-based candidate-free strategies are called for and will likely shed additional light on pathogenic mechanisms of BU.

\section{Conclusion}

In the last decade, human genetics of TB and leprosy susceptibility were extensively studied by genome-wide approaches to complement findings from candidate gene studies in the search of host genetic control of disease susceptibility. Major disease susceptibility loci have been mapped to human 
chromosome regions by GWLS, and, at least for some examples, this was followed by a search for genes that underlie those loci leading to the identification of new candidate susceptibility genes. Regarding GWAS data and replications of those findings, TB and leprosy studies surprised in different ways. In TB, the number of genetic risk factors and their effect size on susceptibility were smaller than expected and replication in different population proved a difficult task. The reason for that is not clear, but it could be due to the heterogeneity of the phenotype, to host-environment interactions or to the variability of the M. tuberculosis genome. In leprosy, GWAS and replication studies provided insights into disease pathogenesis and revealed an unexpected overlap in the genetic control of leprosy and its clinical presentations with common inflammatory disorders such as Crohn's disease. In addition, genome-wide RNA expression analyses in mycobacterial disease contributed valuable data of the hostpathogen interplay leading to gene signatures that might be useful for disease control. These studies also detected new genes and pathways that might help to better understand the cellular response to infection and clinical disease. Finally, despite the debilitating outcomes of BU and perhaps due to lower disease burden, research of the genetics of BU susceptibility is still in its infancy. Application of large scale genome-wide approaches to BU may contribute to a better understanding of the role of human genetic factors in predisposition to $\mathrm{BU}$ and hopefully pave the way for an effective control of this condition.

\section{Compliance with ethical standards}

Conflict of interest The authors declare that they have no conflict of interest.

Open Access This article is distributed under the terms of the Creative Commons Attribution 4.0 International License (http://creativeco mmons.org/licenses/by/4.0/), which permits unrestricted use, distribution, and reproduction in any medium, provided you give appropriate credit to the original author(s) and the source, provide a link to the Creative Commons license, and indicate if changes were made.

\section{References}

Abel L, El-Baghdadi J, Bousfiha AA et al (2014) Human genetics of tuberculosis: a long and winding road. Philos Trans R Soc B 369:20130428. https://doi.org/10.1098/rstb.2013.0428

Abel L, Fellay J, Haas DW et al (2017) Genetics of human susceptibility to active and latent tuberculosis: present knowledge and future perspectives. Lancet Infect Dis 18:e64-e75. https://doi. org/10.1016/S1473-3099(17)30623-0

Adams LA, Möller M, Nebel A et al (2011) Polymorphisms in MC3R promoter and CTSZ 3'UTR are associated with tuberculosis susceptibility. Eur J Hum Genet 19:676-681. https://doi. org/10.1038/ejhg.2011.1
Alcaïs A, Fieschi C, Abel L, Casanova J-L (2005) Tuberculosis in children and adults: two distinct genetic diseases. J Exp Med 202:1617-1621. https://doi.org/10.1084/jem.20052302

Alcaïs A, Alter A, Antoni G et al (2007) Stepwise replication identifies a low-producing lymphotoxin- $\alpha$ allele as a major risk factor for early-onset leprosy. Nat Genet 39:517-522. https://doi. org/10.1038/ng2000

Alcaïs A, Abel L, Casanova JL (2009) Human genetics of infectious diseases: between proof of principle and paradigm. J Clin Invest 119:2506-2514. https://doi.org/10.1172/JCI38111

Alcaïs A, Quintana-Murci L, Thaler DS et al (2010) Life-threatening infectious diseases of childhood: Single-gene inborn errors of immunity? Ann N Y Acad Sci 1214:18-33. https://doi.org/10.1 111/j.1749-6632.2010.05834.x

Aliahmad P, Seksenyan A, Kaye J (2012) The many roles of TOX in the immune system. Curr Opin Immunol 24:173-177. https://doi. org/10.1016/j.coi.2011.12.001

Alter A, De Léséleuc L, Van Thuc N et al (2010) Genetic and functional analysis of common MRC1 exon 7 polymorphisms in leprosy susceptibility. Hum Genet 127:337-348. https://doi. org/10.1007/s00439-009-0775-x

Alter A, Huong NT, Singh M et al (2011) Human leukocyte antigen class I region single-nucleotide polymorphisms are associated with leprosy susceptibility in Vietnam and India. J Infect Dis 203:1274-1281. https://doi.org/10.1093/infdis/jir024

Alter A, Fava VM, Huong NT et al (2013) Linkage disequilibrium pattern and age-at-diagnosis are critical for replicating genetic associations across ethnic groups in leprosy. Hum Genet 132:107116. https://doi.org/10.1007/s00439-012-1227-6

Anderson ST, Kaforou M, Brent AJ et al (2014) Diagnosis of childhood tuberculosis and host RNA expression in Africa. N Engl J Med 370:1712-1723. https://doi.org/10.1056/NEJMoa1303657

Barogui YT, Klis SA, Johnson RC et al (2016) Genetic susceptibility and predictors of paradoxical reactions in Buruli ulcer. PLoS Negl Trop Dis 10:e0004594. https://doi.org/10.1371/journ al.pntd.0004594

Barreiro LB, Tailleux L, Pai AA et al (2012) Deciphering the genetic architecture of variation in the immune response to Mycobacterium tuberculosis infection. Proc Natl Acad Sci USA 109:12041209. https://doi.org/10.1073/pnas.1115761109

Bellamy R, Beyers N, McAdam KPWJ et al (2000) Genetic susceptibility to tuberculosis in Africans: a genome-wide scan. Proc Natl Acad Sci USA 97:8005-8009. https://doi.org/10.1073/ pnas. 140201897

Belone A, de FF, Rosa, Trombone PS APF, et al (2015) Genome-wide screening of mRNA expression in leprosy patients. Front Genet 6:334. https://doi.org/10.3389/fgene.2015.00334

Berrington WR, Macdonald M, Khadge S et al (2010) Common polymorphisms in the NOD2 gene region are associated with leprosy and its reactive states. J Infect Dis 201:1422-1435. https://doi. org/10.1086/651559

Berry MPR, Graham CM, McNab FW et al (2010) An interferon-inducible neutrophil-driven blood transcriptional signature in human tuberculosis. Nature 466:973-977. https://doi.org/10.1038/natur e09247

Bibert S, Bratschi MW, Aboagye SY et al (2017) Susceptibility to Mycobacterium ulcerans disease (Buruli ulcer) is associated with IFNG and iNOS gene polymorphisms. Front Microbiol 8:1903. https://doi.org/10.3389/fmicb.2017.01903

Blankley S, Graham CM, Levin J et al (2016a) A 380-gene meta-signature of active tuberculosis compared with healthy controls. Eur Respir J 47:1873-1876. https://doi.org/10.1183/13993003.02121 $-2015$

Blankley S, Graham CM, Turner J et al (2016b) The transcriptional signature of active tuberculosis reflects symptom status in 
extra-pulmonary and pulmonary tuberculosis. PLoS ONE 11:e0162220. https://doi.org/10.1371/journal.pone.0162220

Boisson-Dupuis S, Bustamante J, El-Baghdadi J et al (2015) Inherited and acquired immunodeficiencies underlying tuberculosis in childhood. Immunol Rev 264:103-120. https://doi.org/10.1111/ imr. 12272

Capela C, Dossou AD, Silva-Gomes R et al (2016) Genetic variation in autophagy-related genes influences the risk and phenotype of Buruli ulcer. PLoS Negl Trop Dis 10:e0004671. https://doi. org/10.1371/journal.pntd.0004671

Cardoso CC, Pereira AC, Brito-de-Souza VN et al (2011a) TNF$308 \mathrm{G}>$ a single nucleotide polymorphism is associated with leprosy among Brazilians: A genetic epidemiology assessment, meta-analysis, and functional study. J Infect Dis 204:1256-1263. https://doi.org/10.1093/infdis/jir521

Cardoso CC, Pereira AC, De Sales Marques C, Moraes MO (2011b) Leprosy susceptibility: genetic variations regulate innate and adaptive immunity, and disease outcome. Future Microbiol 6:533-549. https://doi.org/10.2217/FMB.11.39

Casanova J-L (2015) Severe infectious diseases of childhood as monogenic inborn errors of immunity. Proc Natl Acad Sci USA 112:E7128-E7137. https://doi.org/10.1073/pnas.1521651112

Casanova J-L, Abel L (2013) The genetic theory of infectious diseases: a brief history and selected illustrations. Annu Rev Genom Hum Genet 14:215-243. https://doi.org/10.1146/annurev-genom $-091212-153448$

Cervino ACL, Lakiss S, Sow O et al (2002) Fine mapping of a putative tuberculosis-susceptibility locus on chromosome 15q11-13 in African families. Hum Mol Genet 11:1599-1603. https://doi. org/10.1093/hmg/11.14.1599

Chen ZL, Wei LL, Shi LY et al (2017) Screening and identification of lncRNAs as potential biomarkers for pulmonary tuberculosis. Sci Rep 7:16751. https://doi.org/10.1038/s41598-017-17146-y

Chimusa ER, Zaitlen N, Daya M et al (2014) Genome-wide association study of ancestry-specific TB risk in the South African coloured population. Hum Mol Genet 23:796-809. https://doi. org/10.1093/hmg/ddt462

Chopra R, Ali S, Srivastava AK et al (2013) Mapping of PARK2 and PACRG overlapping regulatory region reveals LD structure and functional variants in association with leprosy in unrelated indian population groups. PLoS Genet 9:e1003578. https://doi. org/10.1371/journal.pgen.1003578

Cobat A, Gallant CJ, Simkin L et al (2009) Two loci control tuberculin skin test reactivity in an area hyperendemic for tuberculosis. $\mathbf{J}$ Exp Med 206:2583-2591. https://doi.org/10.1084/jem.20090892

Cobat A, Abel L, Alcaïs A, Schurr E (2014) A general efficient and flexible approach for genome-wide association analyses of imputed genotypes in family-based designs. Genet Epidemiol 38:560-571. https://doi.org/10.1002/gepi.21842

Cobat A, Poirier C, Hoal E et al (2015) Tuberculin skin test negativity is under tight genetic control of chromosomal region 11p14-15 in settings with different tuberculosis endemicities. J Infect Dis 211:317-321. https://doi.org/10.1093/infdis/jiu446

Cooke GS, Campbell SJ, Bennett S et al (2008) Mapping of a novel susceptibility locus suggests a role for MC3R and CTSZ in human tuberculosis. Am J Respir Crit Care Med 178:203-207. https://doi.org/10.1164/rccm.200710-1554OC

Curtis J, Luo Y, Zenner HL et al (2015) Susceptibility to tuberculosis is associated with variants in the ASAP1 gene encoding a regulator of dendritic cell migration. Nat Genet 47:523-527. https://doi. org/10.1038/ng.3248

Dai Y, Zhang X, Pan H et al (2011) Fine mapping of genetic polymorphisms of pulmonary tuberculosis within chromosome 18q11.2 in the Chinese population: a case-control study. BMC Infect Dis 11:282. https://doi.org/10.1186/1471-2334-11-282 de Léséleuc L, Orlova M, Cobat A et al (2013) PARK2 mediates interleukin 6 and monocyte chemoattractant protein 1 production by human macrophages. PLoS Negl Trop Dis 7:e2015. https://doi. org/10.1371/journal.pntd.0002015

El Baghdadi J, Orlova M, Alter A et al (2006) An autosomal dominant major gene confers predisposition to pulmonary tuberculosis in adults. J Exp Med 203:1679-1684. https://doi.org/10.1084/ jem.20060269

Etna MP, Sinigaglia A, Grassi A et al (2018) Mycobacterium tuberculosis-induced miR-155 subverts autophagy by targeting ATG3 in human dendritic cells. PLoS Pathog 14:e1006790. https://doi. org/10.1371/journal.ppat.1006790

Fava VM, Schurr E (2016) The Complexity of the Host Genetic Contribution to the Human Response to Mycobacterium leprae. In: Scollard D, Gillis T (eds) International Textbook of Leprosy. http://www.internationaltextbookofleprosy.org. pp 1-33

Fava V, Orlova M, Cobat A et al (2012) Genetics of leprosy reactions: an overview. Mem Inst Oswaldo Cruz 107 Suppl:132-142

Fava VM, Cobat A, Van Thuc N et al (2015) Association of TNFSF8 regulatory variants with excessive inflammatory responses but not leprosy per se. J Infect Dis 211:968-977. https://doi. org/10.1093/infdis/jiu566

Fava VM, Manry J, Cobat A et al (2016) A Missense LRRK2 Variant Is a Risk Factor for Excessive Inflammatory Responses in Leprosy. PLoS Negl Trop Dis 10:e0004412. https://doi.org/10.1371/journ al.pntd.0004412

Fava VM, Manry J, Cobat A et al (2017a) A genome wide association study identifies a lncRna as risk factor for pathological inflammatory responses in leprosy. PLoS Genet 13:e1006637. https:// doi.org/10.1371/journal.pgen.1006637

Fava VM, Sales-Marques C, Alcaïs A et al (2017b) Age-dependent association of TNFSF15/TNFSF8 variants and leprosy type 1 reaction. Front Immunol 8:155. https://doi.org/10.3389/fimmu .2017 .00155

Fox GJ, Orlova M, Schurr E (2016) Tuberculosis in newborns: the lessons of the "Lübeck Disaster" (1929-1933). PLoS Pathog 12:e1005271. https://doi.org/10.1371/journal.ppat.1005271

Gaschignard J, Grant AV, Thuc N, Van et al (2016) Pauci- and multibacillary Leprosy: two distinct, genetically neglected diseases. PLoS Negl Trop Dis 10:e0004345. https://doi.org/10.1371/journ al.pntd.0004345

Geluk A, Ottenhoff THM (2006) HLA and leprosy in the pre and postgenomic eras. Hum Immunol 67:439-445. https://doi. org/10.1016/j.humimm.2006.03.009

Grant AV, Alter A, Huong NT et al (2012) Crohn's disease susceptibility genes are associated with leprosy in the Vietnamese population. J Infect Dis 206:1763-1767. https://doi.org/10.1093/infdi s/jis588

Grant AV, El Baghdadi J, Sabri A et al (2013) Age-dependent association between pulmonary tuberculosis and common TOX variants in the 8q12-13 linkage region. Am J Hum Genet 92:407-414. https://doi.org/10.1016/j.ajhg.2013.01.013

Grant AV, Cobat A, Van Thuc N et al (2014) CUBN and NEBL common variants in the chromosome 10p13 linkage region are associated with multibacillary leprosy in Vietnam. Hum Genet 133:883-893. https://doi.org/10.1007/s00439-014-1430-8

Grant AV, Sabri A, Abid A et al (2016) A genome-wide association study of pulmonary tuberculosis in Morocco. Hum Genet 135:299-307. https://doi.org/10.1007/s00439-016-1633-2

Guerreiro LTA, Robottom-Ferreira AB, Ribeiro-Alves M et al (2013) Gene expression profiling specifies chemokine, mitochondrial and lipid metabolism signatures in leprosy. PLoS ONE 8:e64748. https://doi.org/10.1371/journal.pone.0064748

Hashemi M, Eskandari-Nasab E, Moazeni-Roodi A et al (2013) Association of CTSZ rs34069356 and MC3R rs6127698 gene 
polymorphisms with pulmonary tuberculosis. Int J Tuberc Lung Dis 17:1224-1228. https://doi.org/10.5588/ijtld.12.0762

Hu X, Peng W, Chen X et al (2016) No significant effect of ASAP1 gene variants on the susceptibility to tuberculosis in Chinese Population. Med (United States) 95:e3703. https://doi. org/10.1097/MD.0000000000003703

Jarduli LR, Sell AM, Reis PG et al (2013) Role of HLA, KIR, MICA, and cytokines genes in leprosy. Biomed Res Int 2013:989837. https://doi.org/10.1155/2013/989837

Ji L-D, Chai P-F, Zhou B-B et al (2013) Lack of association between polymorphisms from genome-wide association studies and tuberculosis in the Chinese population. Scand J Infect Dis 45:310 314. https://doi.org/10.3109/00365548.2012.726739

Kaforou M, Wright VJ, Oni T et al (2013) Detection of tuberculosis in HIV-infected and -uninfected African adults using whole blood RNA expression signatures: a case-control study. PLoS Med 10:e1001538. https://doi.org/10.1371/journal.pmed.1001538

Lee S-W, Lin C-Y, Chuang T-Y et al (2016) SNP rs4331426 in 18q11.2 is associated with susceptibility to tuberculosis among female Han Taiwanese. J Microbiol Immunol Infect 49:436-438. https ://doi.org/10.1016/j.jmii.2014.11.007

Li J, Liu H, Liu J et al (2012) Association study of the single nucleotide polymorphisms of PARK2 and PACRG with leprosy susceptibility in Chinese population. Eur J Hum Genet 20:488-489. https:// doi.org/10.1038/ejhg.2011.190

Liu Z, Lee J, Krummey S et al (2011) The kinase LRRK2 is a regulator of the transcription factor NFAT that modulates the severity of inflammatory bowel disease. Nat Immunol 12:1063-1070. https ://doi.org/10.1038/ni.2113

Liu H, Irwanto A, Fu X et al (2015) Discovery of six new susceptibility loci and analysis of pleiotropic effects in leprosy. Nat Genet 47:267-271. https://doi.org/10.1038/ng.3212

Liu H, Wang Z, Li Y et al (2017) Genome-wide analysis of proteincoding variants in Leprosy. J Invest Dermatol 137:2544-2551. https://doi.org/10.1016/j.jid.2017.08.004

Maertzdorf J, Repsilber D, Parida SK et al (2011) Human gene expression profiles of susceptibility and resistance in tuberculosis. Genes Immun 12:15-22. https://doi.org/10.1038/gene.2010.51

Maertzdorf J, Tönnies M, Lozza L et al (2018) Mycobacterium tuberculosis invasion of the human lung: first contact. Front Immunol 9:1-12. https://doi.org/10.3389/fimmu.2018.01346

Mahasirimongkol S, Yanai H, Nishida N et al (2009) Genome-wide SNP-based linkage analysis of tuberculosis in Thais. Genes Immun 10:77-83. https://doi.org/10.1038/gene.2008.81

Mahasirimongkol S, Yanai H, Mushiroda T et al (2012) Genome-wide association studies of tuberculosis in Asians identify distinct at-risk locus for young tuberculosis. J Hum Genet 57:363-367. https://doi.org/10.1038/jhg.2012.35

Malhotra D, Darvishi K, Lohra M et al (2006) Association study of major risk single nucleotide polymorphisms in the common regulatory region of PARK2 and PACRG genes with leprosy in an Indian population. Eur J Hum Genet 14:438-442. https://doi. org/10.1038/sj.ejhg.5201563

Manry J, Nédélec Y, Fava VM et al (2017) Deciphering the genetic control of gene expression following Mycobacterium leprae antigen stimulation. PLoS Genet 13:e1006952. https://doi. org/10.1371/journal.pgen.1006952

Manzanillo PS, Ayres JS, Watson RO et al (2013) The ubiquitin ligase parkin mediates resistance to intracellular pathogens. Nature 501:512-516. https://doi.org/10.1038/nature12566

Marcinek P, Jha AN, Shinde V et al (2013) LRRK2 and RIPK2 variants in the NOD 2-mediated signaling pathway are associated with susceptibility to Mycobacterium leprae in Indian populations. PLoS ONE 8:e73103. https://doi.org/10.1371/journ al.pone. 0073103
Medeiros P, da Silva WL, de Oliveira Gimenez BB et al (2016) The GATA3 gene is involved in leprosy susceptibility in Brazilian patients. Infect Genet Evol 39:194-200. https://doi.org/10.1016/j. meegid.2016.01.015

Miao R, Ge H, Xu L et al (2016) Genetic variants at 18q11.2 and 8q24 identified by genome-wide association studies were not associated with pulmonary tuberculosis risk in Chinese population. Infect Genet Evol 40:214-218. https://doi.org/10.1016/j.meegi d.2016.03.005

Miller EN, Jamieson SE, Joberty C et al (2004) Genome-wide scans for leprosy and tuberculosis susceptibility genes in Brazilians. Genes Immun 5:63-67. https://doi.org/10.1038/sj.gene.6364031

Mira MT, Alcaïs A, Van Thuc N et al (2003) Chromosome 6q25 is linked to susceptibility to leprosy in a Vietnamese population. Nat Genet 33:412-415. https://doi.org/10.1038/ng1096

Mira MT, Alcaïs A, Nguyen V et al (2004) Susceptibility to leprosy is associated with PARK2 and PACRG. Nature 427:636-640. https://doi.org/10.1038/nature02326

Nakauchi A, Wong JH, Mahasirimongkol S et al (2016) Identification of ITPA on chromosome 20 as a susceptibility gene for young-onset tuberculosis. Hum Genome Var 3:15067. https:// doi.org/10.1038/hgv.2015.67

O’Brien DP, Robson M, Friedman ND et al (2013) Incidence, clinical spectrum, diagnostic features, treatment and predictors of paradoxical reactions during antibiotic treatment of Mycobacterium ulcerans infections. BMC Infect Dis 13:416. https://doi. org/10.1186/1471-2334-13-416

Omae Y, Toyo-Oka L, Yanai H et al (2017) Pathogen lineage-based genome-wide association study identified CD53 as susceptible locus in tuberculosis. J Hum Genet 62:1015-1022. https://doi. org/10.1038/jhg.2017.82

Orlova M, Schurr E (2010) Genetic architecture of Mycobacterial diseases. In: Mehra N (ed) The HLA complex in biology and medicine: a resource book. Jaypee Brothers Medical Publishers, New Delhi, p 577

Orlova M, Schurr E (2017) Human genomics of Mycobacterium tuberculosis infection and disease. Curr Genet Med Rep 5:125131. https://doi.org/10.1007/s40142-017-0124-7

Orlova M, Di Pietrantonio T, Schurr E (2011) Genetics of infectious diseases: hidden etiologies and common pathways. Clin Chem Lab Med 49:1427-1437. https://doi.org/10.1515/ CCLM.2011.620

Orlova M, Cobat A, Huong NT et al (2013) Gene set signature of reversal reaction type I in leprosy patients. PLoS Genet 9:e1003624. https://doi.org/10.1371/journal.pgen.1003624

Pai M, Behr MA, Dowdy D et al (2016) Tuberculosis. Nat Rev Dis Prim 2:16076. https://doi.org/10.1038/nrdp.2016.76

Png E, Alisjahbana B, Sahiratmadja E et al (2012) A genome wide association study of pulmonary tuberculosis susceptibility in Indonesians. BMC Med Genet 13:5. https://doi. org/10.1186/1471-2350-13-5

Portaels F, Silva MT, Meyers WM (2009) Buruli ulcer. Clin Dermatol 27:291-305. https://doi.org/10.1016/J.CLINDERMAT OL.2008.09.021

Ramos GB, Salomão H, Francio AS et al (2016) Association analysis suggests SOD2 as a newly identified candidate gene associated with leprosy susceptibility. J Infect Dis 214:475-478. https:// doi.org/10.1093/infdis/jiw170

Sales-Marques C, Salomão H, Fava VM et al (2014) NOD2 and CCDC122-LACC1 genes are associated with leprosy susceptibility in Brazilians. Hum Genet 133:1525-1532. https://doi. org/10.1007/s00439-014-1502-9

Sauer MED, Salomão H, Ramos GB et al (2015) Genetics of leprosy: expected and unexpected developments and perspectives. Clin Dermatol 33:99-107. https://doi.org/10.1016/j.clindermat ol.2014.10.001 
Schurr E, Gros P (2009) A common genetic fingerprint in leprosy and Crohn's disease? N Engl J Med 361:2666-2668. https:// doi.org/10.1056/NEJMe0910690

Scriba TJ, Penn-Nicholson A, Shankar S et al (2017) Sequential inflammatory processes define human progression from $M$. tuberculosis infection to tuberculosis disease. PLoS Pathog 13:e1006687. https://doi.org/10.1371/journal.ppat.1006687

Seshadri C, Sedaghat N, Campo M et al (2017) Transcriptional networks are associated with resistance to Mycobacterium tuberculosis infection. PLoS ONE 12:e0175844. https://doi. org/10.1371/journal.pone.0175844

Siddiqui MR, Meisner S, Tosh K et al (2001) A major susceptibility locus for leprosy in India maps to chromosome 10p13. Nat Genet 27:439-441. https://doi.org/10.1038/86958

Siddle KJ, Deschamps M, Tailleux L et al (2014) A genomic portrait of the genetic architecture and regulatory impact of microRNA expression in response to infection. Genome Res 24:850-859. https://doi.org/10.1101/gr.161471.113

Simmons JD, Stein CM, Seshadri C et al (2018) Immunological mechanisms of human resistance to persistent Mycobacterium tuberculosis infection. Nat Rev Immunol. https://doi.org/10.1038/s4157 7-018-0025-3

Sloot R, Schim van der Loeff MF, Kouw PM, Borgdorff MW (2014) Risk of tuberculosis after recent exposure: a 10-year follow-up study of contacts in Amsterdam. Am J Respir Crit Care Med 190:1044-1052. https://doi.org/10.1164/rccm.201406-1159OC

Smith WC, van Brakel W, Gillis T et al (2015) The missing millions: a threat to the elimination of leprosy. PLoS Negl Trop Dis 9:e0003658. https://doi.org/10.1371/journal.pntd.0003658

Soares CT, Trombone APF, Fachin LRV et al (2017) Differential expression of MicroRNAs in leprosy skin lesions. Front Immunol 8:1035. https://doi.org/10.3389/fimmu.2017.01035

Sobota RS, Stein CM, Kodaman N et al (2016) A locus at 5q33.3 confers resistance to tuberculosis in highly susceptible individuals. Am J Hum Genet 98:514-524. https://doi.org/10.1016/j. ajhg.2016.01.015

Sopoh GE, Barogui YT, Johnson RC et al (2010) Family relationship, water contact and occurrence of Buruli ulcer in Benin. PLoS Negl Trop Dis 4:e746. https://doi.org/10.1371/journ al.pntd.0000746

Stein CM, Zalwango S, Malone LL et al (2008) Genome scan of $M$. tuberculosis infection and disease in Ugandans. PLoS ONE 3:e4094. https://doi.org/10.1371/journal.pone.0004094

Stienstra Y, van der Graaf WTA, te Meerman GJ et al (2001) Susceptibility to development of Mycobacterium ulcerans disease: review of possible risk factors. Trop Med Int Heal 6:554-562. https:// doi.org/10.1046/j.1365-3156.2001.00746.x

Stienstra Y, van der Werf TS, Oosterom E et al (2006) Susceptibility to Buruli ulcer is associated with the SLC11A1 (NRAMP1) D543N polymorphism. Genes Immun 7:185-189. https://doi. org/10.1038/sj.gene.6364281

Sveinbjornsson G, Gudbjartsson DF, Halldorsson BV et al (2016) HLA class II sequence variants influence tuberculosis risk in populations of European ancestry. Nat Genet 48:318-322. https://doi. org/10.1038/ng.3498

Thye T, Vannberg FO, Wong SH et al (2010) Genome-wide association analyses identifies a susceptibility locus for tuberculosis on chromosome 18q11.2. Nat Genet 42:739-741. https://doi. org/10.1038/ng.639

Thye T, Owusu-Dabo E, Vannberg FO et al (2012) Common variants at $11 \mathrm{p} 13$ are associated with susceptibility to tuberculosis. Nat Genet 44:257-259. https://doi.org/10.1038/ng.1080

Tosh K, Meisner S, Siddiqui MR et al (2002) A region of chromosome 20 is linked to leprosy susceptibility in a South Indian population. J Infect Dis 186:1190-1193. https://doi.org/10.1086/343806
Vincent QB, Ardant MF, Adeye A et al (2014) Clinical epidemiology of laboratory-confirmed Buruli ulcer in Benin: a cohort study. Lancet Glob Health 2:e422-e430. https://doi.org/10.1016/S2214 $-109 X(14) 70223-2$

Vincent QB, Belkadi A, Fayard C et al (2018) Microdeletion on chromosome 8p23.1 in a familial form of severe Buruli ulcer. PLoS Negl Trop Dis 12:e0006429. https://doi.org/10.1371/journ al.pntd.0006429

von Both U, Berk M, Agapow P-M et al (2018) Mycobacterium tuberculosis exploits a molecular off switch of the immune system for intracellular survival. Sci Rep 8:661. https://doi.org/10.1038/ s41598-017-18528-y

Wallace C, Fitness J, Hennig B et al (2004) Linkage analysis of susceptibility to leprosy type using an IBD regression method. Genes Immun 5:221-225. https://doi.org/10.1038/sj.gene.6364062

Wang X, Tang NLS, Leung CC et al (2013) Association of polymorphisms in the Chr18q11.2 locus with tuberculosis in Chinese population. Hum Genet 132:691-695. https://doi.org/10.1007/ s00439-013-1282-7

Wang D, Xu L, Lv L et al (2015) Association of the LRRK2 genetic polymorphisms with leprosy in Han Chinese from Southwest China. Genes Immun 16:112-119. https://doi.org/10.1038/ gene. 2014.72

Wang Z, Sun Y, Fu X et al (2016) A large-scale genome-wide association and meta-analysis identified four novel susceptibility loci for leprosy. Nat Commun 7:13760. https://doi.org/10.1038/ncomm s13760

Wang Z, Arat S, Magid-Slav M, Brown JR (2018) Meta-analysis of human gene expression in response to Mycobacterium tuberculosis infection reveals potential therapeutic targets. BMC Syst Biol 12:3. https://doi.org/10.1186/s12918-017-0524-z

WHO (2012) Treatment of Mycobacterium Ulcerans Disease (Buruli Ulcer). http://apps.who.int/iris/bitstream/10665/77771/1/97892 41503402_eng.pdfl. Accessed 23 Feb 2018

WHO (2017a) Global Tuberculosis Report 2017. http://www.who.int/ tb/publications/global_report/en/. Accessed 15 Feb 2018

WHO (2017b) Global leprosy update, 2016: accelerating reduction of disease burden. Wkly Epidemiol Rec 501-520

WHO (2017c) Buruli ulcer (Mycobacterium ulcerans infection) - Fact sheet No 199. http://www.who.int/mediacentre/factsheets/fs 199/ en/. Accessed 15 Feb 2018

WHO (2017d) Number of new cases of Buruli ulcer reported: 2016. http://apps.who.int/neglected_diseases/ntddata/buruli/burul i.html. Accessed 15 Feb 2018

Wong SH, Gochhait S, Malhotra D et al (2010a) Leprosy and the adaptation of human toll-like receptor 1. PLoS Pathog 6:1-9. https:// doi.org/10.1371/journal.ppat.1000979

Wong SH, Hill AVS, Vannberg FO, India-Africa-United Kingdom Leprosy Genetics Consortium (2010b) Genomewide association study of leprosy. N Engl J Med 362:1446-1448. https://doi. org/10.1056/NEJMc1001451

Yang Q, Liu H, Low HQ et al (2012) Chromosome 2p14 is linked to susceptibility to leprosy. PLoS ONE 7:e29747. https://doi. org/10.1371/journal.pone.0029747

Zak DE, Penn-Nicholson A, Scriba TJ et al (2016) A blood RNA signature for tuberculosis disease risk: a prospective cohort study. Lancet 387:2312-2322. https://doi.org/10.1016/S0140 -6736(15)01316-1

Zhang F-R, Huang W, Chen S-M et al (2009) Genomewide association study of leprosy. N Engl J Med 361:2609-2618. https://doi. org/10.1056/NEJMoa0903753

Zhang F, Liu H, Chen S et al (2011) Identification of two new loci at IL23R and RAB32 that influence susceptibility to leprosy. Nat Genet 43:1247-1251. https://doi.org/10.1038/ng.973 